\title{
Critical Reflections on Regulation
}

Julia Black

\section{Contents}

Introduction 1

1. Decentered understandings of regulation 2

2. 'Regulation': Can it survive 'decentring'? 8

3. Conceptualising 'regulation' 16

Developing a decentered definition of regulation $\quad 19$

Critiquing a decentered definition of regulation 21

4. Law and regulation 22

5. Conclusion 27 
The support of the Economic and Social Research Council (ESRC) is gratefully acknowledged. The work was part of the programme of the ESRC Centre for Analysis of Risk and Regulation.

Published by the Centre for Analysis of Risk and Regulation at the London School of Economics and Political Science

$$
\text { Houghton Street }
$$

London WC2A 2AE

(C) London School of Economics and Political Science, 2002

ISBN 0753019280

All rights reserved.

No part of this publication may be reproduced, stored in a retrieval system, or transmitted, in any form or by any means, without the prior permission in writing of the publisher, nor be otherwise circulated in any form of binding or cover other than that in which it is published and without a similar condition including this condition being imposed on the subsequent purchaser.

Printed and bound by the reprographics department, LSE, January 2002 


\title{
CRITICAL REFLECTIONS ON REGULATION
}

\author{
Julia Black*
}

Increasingly, regulation is being seen as 'decentred' from the state, and even from the well recognised forums of self-regulation. A decentred analysis has several strands, and seeing the nature and problems of regulation from a decentred perspective can be very stimulating. It opens up the cognitive frame of what 'regulation' is, enabling commentators to spot regulation in previously unsuspected places. It can prompt policy thinkers in academia and government to consider a wide range of different configurations of state, market, community, associations and networks to deliver public policy goals. But a decentred understanding of regulation also raises quite fundamental questions of the nature and understanding of regulation, the consequent role of the state, and our understanding of law. It means we can no longer escape the need to address the question of just what it is that is being 'decentred', of what it is that we want the concept of 'regulation' to do, and what some of the implications of that decision might be. The answers to these questions are at best contested and at worse simply incoherent. It is a debate which is sorely needed, however, and which it is the aim of the paper to promote.

\section{Introduction}

We are familiar with the notion of the 'regulatory state', 1 and even with that of a 'new regulatory state'. We should also begin to take seriously the notion a 'regulatory society' in which we recognise that regulation is not 'centred' on the state, but instead is 'decentred', diffused throughout society. 'Decentred' regulation clearly resonates with the globalisation debate, but its existence and relevance extends beyond it. Much discussion of decentred techniques of regulation is still state-orientated, however. Thus how actors other than the state might be harnessed in the design of hybrid or 'postregulatory' mechanisms usually is debated in the context of considerations of how the state can best act to further public policy objectives. This article is not concerned with regulatory technique, however; and it also seeks to move away from discussions of regulation that presume the state to play any part. It is concerned to explore the conceptual contours of a 'decentred' analysis of regulation, and to consider what that analysis means for our understanding of what 'regulation' is. Once regulation is not seen as something tied exclusively or even predominantly to the state, it is not clear where its boundaries lie either as a social practice, or an academic discipline. The article

\footnotetext{
* ESRC Centre for Analysis of Risk and Regulation and Law Department, London School of Economics and Political Science. Versions of this paper have been delivered as part of the Current Legal Problems lecture series at UCL, London in February 2001, at the conference of the Australian Society of Legal Philosophy in Canberra in June 2001, and at a seminar for the Centre for Analysis of Risk and Regulation, October 2001. I thank participants for their comments, in particular Christine Parker and Dimity Kingsford-Smith. This article was partly written whilst I held a British Academy/Leverhulme Trust Senior Research Fellowship, and I gratefully acknowledge that support. The usual responsibilities remain my own.

${ }^{1}$ Majone, G (1994) 'The Rise of the Regulatory State in Western Europe' West European Politics 17: 77.

${ }^{2}$ Braithwaite, J (2000) 'The New Regulatory State and the Transformation of Criminology’ British Journal of Criminology 40: 222.
} 
thus seeks to explore what conception of regulation is required by, and for, a decentred analysis of regulation to be developed, and explores the implications of such an analysis for our understanding of the relationship between law and regulation.

\section{Decentred understandings of regulation}

'Regulation' is not a concept that travels well, in either a centred or 'decentred' form. As any who have attempted to study 'regulation' outside of English-speaking countries will be aware, there is often no parallel word or even concept, though that does not mean that the social activity to which the term 'regulation' is used to refer does not exist. It is rather simply to observe that different socio-linguistic communities have different terms, with different connotations and meanings. Just what 'regulation' refers to even in English-speaking communities, and how 'regulation' is differentiated from the web of concepts in which it is located, is discussed further below. The focus in this section is on the understandings of the nature of government-society and intra-society relationships on which traditional conceptualisations of regulation have been built, at least where 'regulation' is a recognisable concept, on how these are changing and with what implications for an understanding of 'regulation'.

The core understanding that many have of 'regulation' is some form of 'command and control' (CAC) regulation: regulation by the state through the use of legal rules backed by (often criminal) sanctions. 'CAC' has also however become shorthand to denote all that can be bad about regulation, including poorly targeted rules, rigidity, ossification, under- or over- enforcement, and unintended consequences. The extent to which CAC does or does not live up to this caricature is an empirical question which has been debated elsewhere. ${ }^{3}$ More importantly for this discussion, CAC regulation posits a particular role for the state against which the 'decentring' analysis is counterposed. It is 'centred' in that it assumes the state to have the capacity to command and control, to be the only commander and controller, and to be potentially effective in commanding and controlling. It is assumed to be uni-lateral in its approach (governments telling, others doing), to be based on simple cause-effect relations, and to envisage a linear progression from policy formation through to implementation. Its failings are variously identified as including the following: that the instruments used (laws backed by sanctions) are inappropriate and unsophisticated (instrument failure), that government has insufficient knowledge to be able to identify the causes of problems, to design solutions that are appropriate, and to identify non-compliance (information and knowledge failure), that implementation of the regulation is inadequate (implementation failure), and that those being regulated are insufficiently inclined to comply, and those doing the regulating are insufficiently motivated to regulated in the public interest (motivation failure and capture theory).

As noted, many discussions of CAC regulation to an extent set up a straw man, which can easily be knocked down. Nonetheless, there is a set of alternative perspectives on the nature of government-society, and intra-society interactions which differs to more centred perspectives, with consequences, it is suggested, for how regulation is, and should be conceptualised. The analysis offered here draws together a number of themes from a range of writings in law, regulation and governance which together, it is argued,

\footnotetext{
${ }^{3}$ See Baldwin, R (1997) 'Regulation: After Command and Control' in K Hawkins (ed) The Human Face of Law, Oxford: Oxford University Press; Gunningham, N and Grabovsky, P (1998) Smart Regulation: Designing Environmental Policy, Oxford: Oxford University Press, pp 38-50.
} 
comprise a 'decentred' perspective or understanding of the nature of those interactions. ${ }^{4}$ These writings have both descriptive and prescriptive aspects. Their significance for regulation is that they pose an alternative diagnosis for 'failures' of state-centred action, and, it is argued they require us to reconsider not only how the state might act in order to pursue its goals, but how we should understand 'regulation' itself. For the moment I anticipate the argument below by assuming that we can construct a conceptualisation of regulation that is consistent with the decentring perspective so as to develop an understanding of decentred regulation that will enable us to recognise better how certain forms of power and control are exercised throughout society.

Decentred perspectives share neither the assumptions nor the diagnosis of the 'centred' analysis of regulation, and embrace a far wider set of techniques than the 'rules backed by sanctions' of CAC regulation. Much of the theoretical analysis is rooted in systems theory, though others have reached similar conclusions via other analytical routes, or have used systems theory only lightly in their work. ${ }^{5}$ At the conceptual core of a decentred understanding, it is suggested, are five central notions: complexity, fragmentation, interdependencies, ungovernability, and the rejection of a clear distinction between public and private. In terms of complexity, a decentred understanding of regulation emphasises both causal complexity and the complexity of interactions between actors in society (or systems). There is an increasing recognition that social problems are the result of various interacting factors, not all of which may be known, the nature and relevance of which changes over time, and the interaction between which will be only imperfectly understood. More conceptual writings also draw attention to the dynamic interactions between actors and/or systems, and to the operations of forces which produce a constant tension between stability and change within a system (loosely defined). Those interactions are themselves complex and intricate, and actors are diverse in their goals, intentions, purposes, norms and powers. ${ }^{6}$

Fragmentation refers to fragmentation of knowledge, and fragmentation of power and control. The fragmentation of knowledge is more radically formed than the more familiar problem of the information asymmetry between regulator and regulated: that government cannot know as much about industry as industry does about itself. In a decentred understanding of regulation, it is not assumed that any one actor has all the information necessary to solve social problems: it is not a question of industry having, government needing. Rather, no single actor has all the knowledge required to solve

\footnotetext{
${ }^{4}$ There is no single exposition of a 'decentred understanding', but central to the analysis developed above are the following writings: Teubner, G (ed) (1987) Juridification of the Social Spheres, Berlin: De Gruyter; Teubner, G (ed) (1986) Dilemmas of Law in the Welfare State, Berlin: De Gruyter; Teubner, G and Febbrajo, A (eds) (1992), State, Law, Economy as Autopoietic Systems, Berlin: De Gruyter; Teubner, G, Farmer, L and Murphy, D (1994) Environmental Law and Ecological Responsibility, Chichester: Wiley; Veld, R et al (1991) Autopoiesis and Configuration Theory: New Approaches to Societal Steering, Dordrecht; In the governance literature: Foucault, M (1991) 'Governmentality' in G Burchell, C Gordon, and P Miller The Foucault Effect: Studies in Governmentality, London: Harvester Wheatsheaf; Rose, $\mathrm{N}$ and Miller, P (1992) 'Political Power Beyond the State: Problematics of Government' British Journal of Sociology 43 (2):173; Rose, N (1999) Powers of Freedom, Cambridge: Cambridge University Press; Kooiman, J (ed) (1993) Modern Governance: New Government-Society Interactions, London: Sage; Rose, N (2000) 'Government and Control' British Journal of Criminology 40: 321; Rhodes, R (1997) Understanding Governance, Buckingham. The spirit of decentring is also evident in writings in criminology, see eg Garland, D (2001) The Culture of Control, Oxford: Clarendon.

${ }^{5}$ eg Rhodes, note 4 above.

${ }^{6}$ Kooiman, note 4 above.
} 
complex, diverse and dynamic problems, and no single actor has the overview necessary to employ all the instruments needed to make regulation effective. The problem is sometimes more radically framed to be that not only is knowledge fragmented but that information is socially constructed - there are no such things as 'objective' social truths. This conclusion is arrived at via various theoretical routes, most influential in regulatory writings has been autopoeisis. Autopoietically closed subsystems, such as politics, administration and law, construct their images of other subsystems only through the distorting lens of their own perceptual apparatus, that is through experiences of their environment and in terms of their own binary oppositions. Thus, the information systems possess about other systems is simply that which they have themselves constructed in accordance with their own criteria. ${ }^{7}$ The conclusion is also reached through various strands of new institutionalism, discourse theory, cultural theory and some decision making theories: that is that decision makers, organisations etc, construct images of their environment in their own image, or through their own cognitive frames. ${ }^{8}$

Decentring analyses also draw on Foucauldian notions of power to emphasis that in addition to fragmentation of knowledge there is fragmentation of power and control. Government does not have a monopoly on the exercise of power and control. Rather it is dispersed between social actors and between actors and the state. ${ }^{9}$ Moreover, as many have observed, the regulatory systems existing within social spheres are seen as equally, if not more, important to social ordering as the formal ordering of the state. Regulation occurs in many locations, in many fora; there is 'regulation in many rooms'. ${ }^{10}$

Observations of fragmentation relate to the third central aspect of a decentring analysis, and that is the autonomy and ungovernability of actors (or systems). Autonomy is not used in the sense of freedom from interference by government, rather it is the idea that actors will continue to develop or act in their own way in the absence of intervention. Actors or systems are self regulating, and regulation cannot take their behaviour as a constant. Regulation is, as Foucault said of governance, the "conduct of conduct', ${ }^{11}$ or as re-phrased by Rose, 'to act upon action'. ${ }^{12}$ This has several implications, first and most obviously that regulation will produce changes in behaviour and outcomes that are unintended (though not necessarily adverse), a well recognised empirical phenomenon in regulation. ${ }^{13}$ Second, that its form may have to vary depending on the attitude of the regulatee towards compliance, an attitude which it can itself affect, again recognised in

\footnotetext{
${ }^{7}$ See Teubner, note 4 above.

${ }^{8}$ See eg DiMaggio, P and Powell, W (1991) 'Introduction' in W Powell and P DiMaggio (eds), The New Institutionalism in Organisational Analysis, Princeton: Princeton University Press; Foucault, M (1991) 'Politics and the Study of Discourse' in G Burchell et al, not 4 above; Schwarz, M and Thompson, M (1990) Divided we Stand, Hemel Hempstead: Harvester Wheatsheaf; Hawkins, K and Manning, P (1990) 'Legal Decisions: A Frame Analytic Perspective' in S H Riggins (ed) Beyond Goffman: Studies on Communication, Institution and Social Interaction, Berlin: De Gruyter.

${ }^{9}$ Foucault, note 4 above; Rose and Miller, note 4 above; Gordon, C (1991) 'Governmental Rationality: An Introduction' in Burchell et al (eds), note 4 above.

${ }^{10}$ See eg Nader, L and Nader, C (1985) 'A Wide Angle on Regulation: An Anthropological

Perspective' in Noll, R (ed), Regulatory Policy and the Social Sciences, Berkeley: University of California Press.

${ }^{11}$ See Foucault, note 4 above; Gordon, note 9 above.

${ }^{12}$ Rose (1999), note 4 above, p 4.

${ }^{13}$ See eg Grabovsky, P (1995) 'Counterproductive Regulation' in International Journal of Sociology of Law 23: 347 .
} 
practice in regulatory literature. ${ }^{14}$ Third, that no single actor can hope to dominate the regulatory process unilaterally as all actors can be severely restricted in reaching their own objectives not just by limitations in their own knowledge but also by the autonomy of others, ${ }^{15}$ a clear counterpoint to the assumptions of theories of 'regulatory capture'. Whether that is because of the actors' capacity to employ power and resources for action, ${ }^{16}$ or because of the inherent characteristics of the system, or for some other reason, is a moot point. Fifthly, that the autonomy of the actor will to an extent render it insusceptible to external regulation. Here, autopoiesis has the more radical analysis of autonomy. Autopoeticists diverge on the meaning of autonomy, but broadly it refers to the self-regulation, self-production and self-organisation of systems which are normatively closed but cognitively open. ${ }^{17}$ The consequence: that no system can act directly upon another. Attempts to do so will result in Teubner's well known regulatory trilemma: the indifference of the 'target' system to the intervention, the destruction of the 'target' system itself, or the destruction of the intervening system. ${ }^{18}$ Finally, that subjects or systems have the capacity to regulate themselves, a capacity that has to be harnessed for 'government at a distance' to be effective.

Observations of fragmentation and autonomy relate to the fourth central aspect of a decentring analysis: interactions and interdependencies. A decentring analysis has as part of its core the existence and complexity of interactions and interdependencies between social actors, and between social actors and government in the process of regulation. ${ }^{19}$ Regulation is a two-way, or three or four-way process, between all those involved in the regulatory process, and particularly between regulator and regulatee in the implementation of regulation. In Offe's terms, regulation is 'co-produced'. 20 However the relationship is not seen to be one in which society has needs (problems) and government has capacities (solutions). Rather each is seen as having both problems (needs) and solutions (capacities), and as being mutually dependent on each other for their resolution and use. ${ }^{21}$ These interactions and interdependencies should not be presumed to be contained within national territorial borders: analyses of globalisation emphasise that they may extend well beyond them.

\footnotetext{
${ }^{14}$ See eg Kagan, R and Scholz, J (1984) 'Regulatory Enforcement Strategies' in K Hawkins and J Thomas (eds) Enforcing Regulation, Boston: Kluwer; Baldwin, R (1995) Rules and Government, Oxford: Oxford University Press; McBarnet, D and Whelan, C (1991)'The Elusive Spirit of the Law: Formalism and the Struggle for Legal Control' Modern Law Review 54: 848.

${ }^{15}$ Kooiman, J (1993) 'Governance and Governability: Using Complexity, Dynamics and Diversity' in J Kooiman (ed), note 4 above, pp 44-47.

${ }^{16}$ See eg Mayntz who argues that highly institutionalised and organised subsystems may resist political control, but argues that it is not their self-referential closure which makes intervention difficult but the actions of identifiable actors in resisting intervention/creating autonomy by employing the power resources and capacities for collective action characteristic of highly organised societal sectors: Maytnz, R (1993) 'Governing Failures and the Problem of Governability: Some Comments on a Theoretical Paradigm' in J Kooiman (ed), note 4 above, p 17.

${ }^{17}$ See Teubner, G (1993) Law as an Autopoietic System, Oxford: Oxford University Press, pp 32-34.

${ }^{18}$ Teubner, G (1987) 'Juridification: Concepts, Aspects, Limits, Solutions' in G Teubner (ed), note 4 above.

${ }^{19}$ See eg Kooiman, J (1993) 'Findings, Speculations and Recommendations' in J Kooiman (ed), note 4 above, p 253; Rhodes, note 4 above, pp 50-59; Rose, note 4 above, chapter 1; Hancher, L and Moran, M (1989) 'Organizing Regulatory Space' in L Hancher and M Moran (eds) (1989) Capitalism, Culture and Economic Regulation, Oxford: Oxford University Press.

${ }^{20}$ Offe, C (1984) Contradictions of the Welfare State, London: Hutchinson, p 310; Black, J (1998)

'Talking About Regulation' in Public Law 77.

${ }^{21}$ Kooiman, note 15 above.
} 
The claim that governance and regulation are the product of interactions and interdependencies, leads into the fifth aspect of a decentred perspective. It is the collapse of the public/private distinction in socio-political terms, and, more challenging to our understanding of what 'regulation' is, a rethinking of the role of formal authority in governance and regulation. In decentred analyses, regulation 'happens' in the absence of formal legal sanction - it is the product of interactions, not of the exercise of the formal, constitutionally recognised authority of government. ${ }^{22}$ The collapse of the public/private distinction as a useful tool for analysing governance and regulation is manifested in the identification of 'hybrid' organisations or networks that combine governmental and non-governmental actors in a variety of ways. To the governing alternatives of bureaucracies (hierarchies) and markets have been added associations the 'private interest governments' identified by Streeck and Schmitter which comprised the new corporatism. The concept of authority still played a role, however, for these organisations shared in the state's authority to make and enforce binding decisions'. ${ }^{23}$ Added more recently are networks: the interactions of a range of actors, of which the state is only one, and which it has been argued government both does use and should use to govern. ${ }^{24}$ Governance, and regulation, is seen by some to be the outcome of the interactions of networks, or alternatively 'webs of influence' which operate in the absence of formal governmental or legal sanction. ${ }^{25}$ In a decentred understanding of regulation, therefore, formal de lege authority plays an ambiguous role, and regulation is not so much an activity as a product of activity.

Complexity, fragmentation of knowledge and of the exercise of power and control, autonomy, interactions and interdependencies, and the collapse of the public/private distinction are the central elements of the composite 'decentred understanding' of regulation. Together they suggest a diagnosis of regulatory failure which is based on the dynamics, complexity and diversity of economic and social life, and in the inherent ungovernability of social actors, systems and networks.

There is a set of prescriptions as to the types of regulatory strategies that should be adopted which is tied more or less loosely to this conceptual base. The hallmarks of these 'decentred' strategies are that they are hybrid (combining governmental and nongovernmental actors), multi-faceted (using a number of different strategies simultaneously or sequentially), and they are indirect. ${ }^{26}$ The diagnosis of regulatory failure provided by the decentring analysis suggests that regulation should be a process of co-ordinating, steering, influencing and balancing interactions between actors/systems, and of creating new patterns of interaction which enable social actors/systems to organise themselves, using such techniques as proceduralisation, collibration, feedback loops, redundancy, and above all, countering variety with variety. ${ }^{27}$ The impetus for many of these prescriptions comes from autopoiesis: the functional differentiation of society into cognitively closed, normatively open self referential systems, though analyses of the tools of regulation to be employed may only

\footnotetext{
${ }^{22}$ Rhodes, note 3 above.

${ }^{23}$ Streeck, P and Schmitter, P (1985) 'Community, Market, State and Associations? The Prospective Contribution of Interest Governance to Social Order' in P Streeck and P Schmitter (eds), Private Interest Government: Beyond Market and State, London: Sage, p 20.

${ }^{24}$ See eg Rose, note 4 above, 16 et seq.

${ }^{25}$ Rhodes, note 4 above, Braithwaite, J and Drahos, P (2000) Global Business Regulation, Oxford: Oxford University Press.

${ }^{26}$ eg Teubner, note 4 above and related analyses.

${ }^{27}$ References at note 4 above.
} 
be weakly attached to this particular theoretical base. In most instances, discussion occurs in the context of how the state should design regulatory mechanisms in order to achieve its objectives, and indeed some have been labelled as the strategies of the 'new regulatory state'. ${ }^{28}$ The role that the state plays in any of them will range from full participant to mere guiding hand or threatening shadow. The decentring analysis suggests however that similar forms of strategies will have to be used whether or not the state is present at all, even in ghostly form. What conceptualisation of regulation is then invoked is the issue in debate, and whether or not the state has to play some part in such arrangements for them to be 'regulation', albeit of a decentred kind, is considered further below.

It is worth noting before we enter that debate that whilst there may be consensus on the range of techniques that should be considered, there is less consensus on the particular normative goals that should be achieved in using such strategies. For many, the goal of regulation is the project of welfare economics: the correction of market failure, and traditional conceptualisations of 'regulation' have assumed it to be an activity directed principally towards that objective (and correspondingly, anything that was not so directed was not 'regulation'). In the standard treatments of 'regulation', the 'why regulate?' question is nearly always answered in terms of the correction of market failures, with the occasional nod to distributional or other ancillary aims. ${ }^{29}$ However, that goal is being displaced, and others added. Notably, the management and distribution of risk: regulating the 'risk society' is a burgeoning academic and policy area and there are signs that existing systems of regulation, for example UK financial services, are coupling the correction of market failure with the management of risk as their organising principles. Other goals which it is argued regulation should pursue, in particular by those coming from a socio-legal base, are access to justice, ${ }^{30}$ or legitimacy, ${ }^{31}$ or the achievement of social justice in some form. ${ }^{32}$ Alternatively, normative goals are sometimes framed functionally as in Teubner's version of systems theory, in which the normative goals of regulation must be to create the conditions for responsiveness, to prevent the entropy or self destruction of systems, and to stimulate system integration. ${ }^{33}$ Whether those normative goals are confined to systems of regulation in which the state is involved, or whether they extend to regulation conducted by all social actors (assuming we can extend 'regulation' beyond the state), is an equally contentious debate. ${ }^{34}$

\footnotetext{
${ }^{28}$ Braithwaite, note above; Parker, C (2000) 'Reinventing Regulation within the Corporation: Compliance Oriented Regulatory Innovation' in Administration \& Society 35 (2): 529; Parker, C (forthcoming) The Open Corporation: Self-Regulation and Corporate Citizenship

${ }^{29}$ eg Breyer, S (1982) Regulation and its Reform, Harvard; Ogus, A (1994) Regulation: Legal Form and Economic Theory, Oxford: Oxford University Press; Baldwin, R and Cave, M (1999) Understanding Regulation, Oxford: Oxford University Press.

${ }^{30}$ Parker, C (1999) Just Lawyers, Oxford: Oxford University Press.

${ }^{31}$ Baldwin and Cave, note 29 above; Baldwin, R (1995) Rules and Government, Oxford: Oxford University Press.

${ }^{32}$ Ayres, I and Braithwaite, J (1992) Responsive Regulation, Oxford: Oxford University Press, chapter 3 (tripartism); or the extension of participative forms of polity building into regulation: Black, J (2000/01) 'Proceduralising Regulation: Part I' Oxford Journal of Legal Studies 20: 597-614, id., 'Proceduralising Regulation: Part II' Oxford Journal of Legal Studies 21: 33-59.

${ }^{33}$ Teubner (1983), note 4 and 18 above; Teubner, G 'Substantive and Reflexive Elements in Modern Law' Law and Society Review 17: 239.

${ }^{34}$ For an argument on the 'horizontality' as well as 'verticality' of rights and obligations see eg Habermas, J (1999) Between Facts and Norms (translation) Oxford: Polity.
} 


\section{2. 'Regulation': can it survive 'decentring'?}

Seeing the nature and problems of regulation from a decentred perspective can be very stimulating. It can open up the conceptualisation, and thus cognitive frame, of what 'regulation' is, enabling commentators to spot regulation in previously unsuspected places. It also has a significant practical dimension for it can facilitate policy thinking inside and outside academia, enabling policy makers to consider a wide range of different configurations of state, market, community, associations and networks to deliver public policy goals. It can also facilitate an understanding of how 'regulation' does and might occur in societies where the state does not have the capacity to function in a 'centred' way, for example in some less developed economies. It can also be very perplexing. For a decentred understanding of regulation raises a quite fundamental conceptual question. Once regulation loses its analytical link to the state, and ceases to describe a particular form of state-society interaction, what does it become? The answer is not at all clear.

Conceptual confusion is indicated by definitional chaos. Not only does 'regulation' not travel as a term, as noted above, even amongst those for whom it does have some meaning, it resonates differently. That is in part a result of the plethora of disciplinary backgrounds of those that seek to analyse 'regulation' in both policy and academic circles. One might ask whether this is such a problem. Indeed, such definitional vagueness is seen by those who write about regulation to be at best a rather quaint feature and at worst an occupational hazard. But some clarity is needed, it is argued, particularly if we are to take the decentring analysis seriously, and if we are to see regulation as something that need not involve the state, and indeed as something to which the state can itself be subject to. Without such clarification, any debate about whether there is regulation, whether there should be, and the forms that it could take will be confused and stultified.

It could be argued that there are already accepted understandings of what 'regulation' is. The main textbooks on regulation identify three definitions. ${ }^{35}$ In the first, regulation is the promulgation of rules by government accompanied by mechanisms for monitoring and enforcement, usually assumed to be performed through a specialist public agency. In the second, it is any form of direct state intervention in the economy, whatever form that intervention might take. In the third, regulation is all mechanisms of social control or influence affecting all aspects of behaviour from whatever source, whether they are intentional or not. ${ }^{36}$

The first two are clearly 'centred' definitions. As should be clear, on these conceptualisations, the discussion above on 'decentred regulation' simply does not make sense: regulation is a state activity; once it is separated from the state 'it' (whatever 'it' is) is not regulation but something else. Only the third definition breaks the connection with the state, but provides no boundaries as to where regulation might end, and some other influencing factor take effect, and so provides very little analytical purchase.

\footnotetext{
${ }^{35}$ Baldwin, R, Scott, C and Hood, C (1998) A Reader on Regulation, Oxford: Oxford University Press; Baldwin and Cave, note 29 above.

${ }^{36}$ See Baldwin, Scott and Hood, ibid, 3; Baldwin and Cave, ibid, 2.
} 
A quick survey of some government publications on 'better regulation' shows the dominance of centred conceptualisations of regulation, and indeed that a narrower one even than the first two set out above is often adopted. In these publications, 'regulation' is used to refer simply to the use of legal instruments, with no presumption as to the existence of systems of monitoring and enforcement. The OECD, for example, defines regulation as 'the full range of legal instruments by which governing institutions, at all levels of government, impose obligations or constraints on private sector behaviour. Constitutions, parliamentary laws, subordinate legislation, decrees, orders, norms, licences, plans, codes and even some forms of administrative guidance can all be considered as 'regulation". 37 The governments of Canada and Australia adopt a similar definition. ${ }^{38}$ Everything that government does that is not done through legislation or delegated legislation is thus not 'regulation'. In contrast, the UK government's Better Regulation Taskforce (BRT) defines regulation as 'any government measure or intervention that seeks to change the behaviour of individuals or groups, so including taxes, subsidies and other financial measures. ${ }^{39}$ Government is, however, a notoriously fragmented thing. Whilst the BRT sees only on government actions to be regulation, Oftel includes in its definition of regulation the operation of market forces. ${ }^{40}$

Academics are even less disciplined. They (including myself) vary as to which of the above definitions they adopt, if any of them, and the same writers may implicitly or explicitly adopt different definitions in different writings. Just to take some of the more recent books on regulation: Baldwin, Scott and Hood adopt all three definitions in the introduction to their Reader on Regulation; ${ }^{41}$ Baldwin and Cave adopt the first two in their book Understanding Regulation, although add 'decentred' potential with the variation that regulation is also the making, monitoring and enforcing of rules by nongovernmental actors. ${ }^{42}$ Hood et al adopt only the first definition in their book, Regulation inside Government, with the additional twist that the 'regulator' has some kind of official mandate to scrutinize the behaviour of the 'regulatee' and seek to change it. ${ }^{43}$ Hall, Hood and Scott however implicitly adopt the third definition in their book on telecommunications regulation when they talk of regulators being 'regulated' by culture. $^{44}$

How 'regulation' is conceptualised often depends on the problem or issue that the writer is focusing on. It is thus not surprising that in their discussion of global business regulation, a decentred definition is also adopted by Braithwaite and Drahos. They equate regulation with the norms, standards, principles and rules that govern commerce and their enforcement. ${ }^{45}$ In their view, governments are regulated by, for example,

\footnotetext{
${ }^{37}$ OECD, Recommendation of the Council of the OECD on Improving the Quality of Government Regulation, OCDE/GD(95)95, Note 1; OECD (1997) The OECD Report on Regulatory Reform: Synthesis, Paris.

${ }^{38}$ Canada: (1994) Regulatory Affairs Guide, Assessing Regulatory Alternatives, Ontario, p 63; Australia: Productivity Commission, Office of Regulatory Review (1999) A Guide to Regulation, $2^{\text {nd }}$ ed, Canberra.

${ }^{39}$ Better Regulation Taskforce (undated) Principles of Better Regulation, London: Cabinet Office, p 1.

${ }^{40}$ Oftel (2000) Encouraging Self- and Co-Regulation in Telecoms to Benefit Consumers, London, p 2.

${ }^{41}$ Baldwin, R, Scott C, and Hood, C 'Introduction', in Baldwin, Scott and Hood, note 35 above.

${ }^{42}$ Hood, C, Scott, C, James, O, Jones, G and Travers, T (2000) Regulation Inside Government, Oxford: Oxford University Press.

${ }^{43}$ Ibid, 8.

${ }^{44}$ Hall, C, Scott, C and Hood, C (1999) Telecommunications Regulation: Culture, Chaos and

Interdependency inside the Regulatory Process, London: Routledge, pp 5-7.

${ }^{45}$ Braithwaite and Drahos, note 25 above, p 10.
} 
Standard and Poor's and Moody's ratings of the bonds they issue. ${ }^{46}$ Another variant on the third definition is provided by Gunningham and Grabovsky who in their book Smart Regulation use 'regulation' to include the forms of social control available to harness a wide range of actors in addressing a particular problem or set of problems - in their case, those related to the environment. ${ }^{47}$

These variations on a 'decentred' definition nonetheless differ as to the role played by intentionality and the problem solving nature of regulation. For example, Hall, Hood and Scott in stating that culture 'regulates' implicitly see no need for intentionality, or a problem-solving orientation, whereas this is central to Gunningham and Grabovsky's understanding of 'regulation'. The different positions on the role of intentionality may be due to the different vantage points for observing regulation. Gunningham and Grabovsky take the more usual vantage point of the regulator and ask what tools are available to it to solve particular problems. In saying regulators are 'regulated' by culture, or even governments by credit ratings firms the perspective adopted is that of the regulated - what forces are they subject to. In the former regulation is an activity, in the latter, it is the product of an activity as well as, perhaps, an activity itself.

The place of power and authority in understandings and definitions of regulation also varies. As noted, Hood et al in Regulation Inside Government explicitly include the fact that a person or body has an official mandate (authority) to attempt to control behaviour in their definition of regulation. However, Hall, Scott and Hood, in suggesting that culture 'regulates', separate regulation from the exercise of authority, or indeed power. Braithwaite and Drahos, however, in drawing attention to the 'regulatory' role of rating agencies, implicitly incorporate a notion of power into their understanding of 'regulation', whilst emphasising the absence of authority.

There is also frequently an implicit or explicit assumption that the target of regulation is an economic actor: a business, or a consumer (this is so whether the regulation is seen as 'economic' or 'social', for the terms 'economic' and 'social' regulation are usually used to refer to the objectives of the regulation, not its location). ${ }^{48}$ Thus for Ogus, 'regulation is fundamentally a politico-economic concept and, as such, can best be understood by reference to different systems of economic organization and the legal forms which maintain them. ${ }^{49}$ Regulation is the means by which the state 'seeks to encourage or direct behaviour which it is assumed would not occur without such intervention' and as such should be seen as distinct from the operation of the markets, even though the latter is underpinned by legal rules. ${ }^{50}$ Baldwin and Cave see 'regulation' to include the use of any tool by government to intervene in the economy, and also to include the use of rules by non government actors to influence the behaviour

\footnotetext{
${ }^{46}$ Ibid, 27.

${ }^{47}$ Gunningham, N and Grabovsky, P (1999) Smart Regulation, Oxford: Oxford University Press, p 4.

${ }^{48}$ Hawkins and Hutter define 'economic' regulation as regulation of financial markets, prices and profits, and 'social' regulation as laws protecting the environment, consumers, and employees: Hawkins, K and Hutter, B (1993) 'The Response of Business to Social Regulation in England and Wales: An Enforcement Perspective' in Law and Policy 15 (3); Hutter, B (1997) 'Compliance: Regulation and Environment', Oxford: Oxford University Press, p 7; Yeager, P (1991), The Limits of the Law: The Public Regulation of Private Pollution, Cambridge: Cambridge University Press, p 24.

${ }^{49}$ Ogus, note 29 above, p 1.

${ }^{50}$ Ibid.
} 
of businesses. ${ }^{51}$ The New Palgrave Dictionary defines 'regulation' as 'the imposition of economic controls by government agencies on (usually) private businesses'. 52

Definitions of 'regulation' implicit in the term 'regulatory state' seem even more narrow. The counterpoint to the 'regulatory state' is the 'welfare state', and 'regulatory state' is used to describe the shift in the style of governance from the direct provision of public services to their provision by others under government supervision. ${ }^{53}$ 'Regulatory' thus suggests that 'regulation' covers only those functions which were previously part of the welfare state. In this, the definition is akin to the older definition of 'regulation', that is the control of businesses providing public utilities. ${ }^{54}$ It should be noted, however that the counterpoint to the 'new regulatory state' hypothesis is not simply the 'regulatory state' as per Majone as such, but 'CAC' regulation as it applies across social and economic life. The 'new' in 'new regulatory state' denotes new techniques of regulation in any of those areas, not just new forms of service delivery in the context of the welfare state.

In contrast, others have broadened the social field in which 'regulation' occurs from the economic sphere to any sphere of social action: the family, ${ }^{55}$ reproduction, ${ }^{56}$ government bureaucrats, ${ }^{57}$ all have been described as objects of 'regulation'. 'Regulators' are also being broadened from the state and some self regulatory associations to other actors (committees, firms, epistemic communities, rating agencies, contracting individuals) and to other 'factors': norms, culture etc. The broad definition of both actors and factors serves those who write in regulation well for it opens up pretty much the whole of social science to their (our!) imperial domain. Indeed, whilst in the broad definition given to 'regulation' in Europe, as encompassing all forms of legislation, governance and social control, has been cited as the reason why the study of 'regulation' had not emerged outside the US by the late 1980 s as an academic (sub)discipline in its own right, ${ }^{58}$ that broad definition is now providing 'regulationists' with a seemingly endless territory ripe for colonisation.

Thus even identifying three definitions glosses over the multiplicity of meanings given to regulation. To illustrate the point, I have made an attempt to indicate the everexpanding nature of 'regulation' in the following table. ${ }^{59}$ I have somewhat artificially grouped the different set of meanings/applications into five: what it is assumed 'regulation' is; who or what is performing it; what institutional or organisational form the regulation is assumed to take; with respect to what actors or areas of social life is it occurring, and how regulation is conducted, through what mechanisms, instruments and techniques.

\footnotetext{
${ }^{51}$ Baldwin and Cave, note 29 above, p 2 \& 63.

${ }^{52}$ Newman, P (ed)(1998) New Palgrave Dictionary of Economics and the Law, Vol 3, London: Palgrave.

${ }^{53}$ Majone, note 1 above.

${ }^{54}$ The definition employed in the International Encyclopaedia of the Social Sciences, Vol 13 (1968)

London: Collier Macmillan.

${ }^{55}$ Eekelaar, J (1991) Regulating Divorce, Oxford: Clarendon; Sangster, J (2001) Regulating Girls and Women: Sexuality, Family and the Law in Ontario, 1920-1960, Oxford: Oxford University Press.

${ }^{56}$ Jackson, E (2001) Regulating Reproduction: Law, Technology and Autonomy, Oxford: Hart.

${ }^{57}$ Hood et al, note 42 above.

${ }^{58}$ Majone, G 'Introduction' in G Majone (ed) (1990) Deregulation or Re-Regulation? Regulatory

Reform in Europe and the United States, London: Pinter, $\mathrm{p} 1$.

${ }^{59}$ Those of the UK, US, Australia and Canada, and the OECD.
} 
Table 1: Regulation - an ever-expanding concept

\begin{tabular}{|c|c|c|c|c|}
\hline $\begin{array}{l}\text { (A) } \\
\text { What is regulation? }\end{array}$ & $\begin{array}{l}\text { (B) } \\
\text { Who or what } \\
\text { does it? }\end{array}$ & $\begin{array}{l}\text { (C) } \\
\text { What form does it } \\
\text { take? }\end{array}$ & $\begin{array}{l}\text { (D) } \\
\text { With respect to } \\
\text { what actors or } \\
\text { area of life? }\end{array}$ & $\begin{array}{l}\text { (E) } \\
\text { How is it done, via } \\
\text { what instruments/ } \\
\text { techniques? }\end{array}$ \\
\hline $\begin{array}{l}\text { A type of legal instrument } \\
\text { A process of: } \\
\text { 'controlling, governing or } \\
\text { directing' (OED) } \\
\text { 'altering or controlling } \\
\text { with reference to some } \\
\text { standard or purpose' } \\
\text { (OED) }\end{array}$ & $\begin{array}{l}\text { State } \\
\text { institutions } \\
\text { (regional, } \\
\text { national, } \\
\text { 'extra' } \\
\text { national) }\end{array}$ & $\begin{array}{l}\text { - } \text { ministries, } \\
\text { departments, } \\
\text { agencies } \\
\text { - } \text { supra-national } \\
\text { bodies (EU) } \\
\text { - international } \\
\text { bodies (eg WTO) } \\
\text { - courts }\end{array}$ & $\begin{array}{l}\text { - economic } \\
\text { (firms, markets) } \\
\text { - any other } \\
\text { (family, } \\
\text { education, health, } \\
\text { government etc) }\end{array}$ & $\begin{array}{l}\text { - rules (legal, } \\
\text { 'quasi-legal' non- } \\
\text { legal, universal, } \\
\text { sectoral, bilateral) } \\
\text { - other instruments } \\
\text { (financial, market } \\
\text { based, } \\
\text { information) } \\
\text { - monitoring } \\
\text { - } \text { sanctioning }\end{array}$ \\
\hline $\begin{array}{l}\text { enabling/facilitating } \\
\text { co-ordinating } \\
\text { influencing } \\
\text { conferring a pattern on } \\
\text { something, ordering } \\
\text { rendering constant } \\
\text { And the process is: }\end{array}$ & $\begin{array}{l}\text { Non-state } \\
\text { institutions/act } \\
\text { ors }\end{array}$ & $\begin{array}{l}\text { eg } \\
\text { - associations } \\
\text { - committees } \\
\text { - firms } \\
\text { - individuals } \\
\text { - epistemic } \\
\text { communities } \\
\text { - networks }\end{array}$ & $\begin{array}{l}\text { - economic } \\
\text { - any other }\end{array}$ & $\begin{array}{l}\text { - rules (legal, } \\
\text { 'quasi-legal', non- } \\
\text { legal; multi- } \\
\text { lateral, bi-lateral, } \\
\text { unilateral) } \\
\text { - other instruments } \\
\text { (financial, market } \\
\text { based, infor- } \\
\text { mation) } \\
\text { - monitoring } \\
\text { - sanctioning } \\
\text { - trust }\end{array}$ \\
\hline $\begin{array}{l}\text { intentional } \\
\text { goal directed, problem } \\
\text { solving }\end{array}$ & $\begin{array}{l}\text { Economic } \\
\text { forces }\end{array}$ & - market & $\begin{array}{l}\text { - economic } \\
\text { - any other }\end{array}$ & $\begin{array}{l}\text { - interaction of } \\
\text { rational actors }\end{array}$ \\
\hline $\begin{array}{l}\text { An outcome - the result of } \\
\text { the interaction of } \\
\text { actors/networks/ 'forces' } \\
\text { A property of self } \\
\text { correction. } \\
\text { A property whereby the } \\
\text { nature and growth of parts of } \\
\text { an organism are interrelated } \\
\text { so as to produce an }\end{array}$ & 'Social forces' & $\begin{array}{l}\text { eg } \\
\text { - norms } \\
\text { - institutions } \\
\text { - language } \\
\text { - cognitive frames } \\
\text { - culture } \\
\text { - systems } \\
\text { - networks }\end{array}$ & $\begin{array}{l}\text { - economic } \\
\text { - any other }\end{array}$ & $\begin{array}{l}\text { eg } \\
\text { - structuring } \\
\text { - framing } \\
\text { - enabling } \\
\text { - co-ordinating } \\
\text { - ordering } \\
\text { - translating } \\
\text { - self-referential } \\
\text { reproduction } \\
\end{array}$ \\
\hline $\begin{array}{l}\text { integrated whole, enabling } \\
\text { adaptation (biology) }\end{array}$ & 'Technologies' & $\begin{array}{l}\text { Understandings of } \\
\text { and ability to } \\
\text { manipulate physical } \\
\text { and human } \\
\text { environment }\end{array}$ & - any & $\begin{array}{l}\text { products of those } \\
\text { understandings, } \\
\text { eg statistics, } \\
\text { probabilities, } \\
\text { engineering, IT }\end{array}$ \\
\hline
\end{tabular}


The first group of meanings concerns what the phenomenon is that the commentator on 'regulation' is concerned with. Sometimes, as noted above, regulation is seen simply as a type of legal instrument. Sometimes it is seen as an action, sometimes as an outcome, sometimes as a property. As an action, the dictionary definitions of 'regulation' are controlling, governing, directing, altering, adjusting with reference to some standard or purpose. $^{60}$ These are reflected in part of one of the more central definitions of 'regulation' used in the literature, Selznick's definition of regulation as 'sustained and focused control ${ }^{61}$ (which has the additional elaboration on the dictionary definitions in that the control is systematic rather than ad hoc). Any walk through the regulatory literature soon throws up meanings other than the dictionary definition, however. Regulation is used additionally to mean co-ordinating, ordering (eg 'regulation by the market' $)^{62}$, and facilitating. ${ }^{63}$ Others distinguish 'regulation' from 'control'. ${ }^{64}$ Further, whilst most writers assume that there is some intentionality involved - the intention to affect behaviour, even if there may be unintended consequences or side effects, others use the term 'regulation' to refer to those incidental side effects (outcomes) of action that had a quite separate primary intention or purpose (if it had any at all). 'Regulation by the market' denies any intentionality need be involved in regulation, for example. Autopoiesis adopts a very specific meaning for 'regulation', at least when used to refer to 'self regulation', that is, dynamic structural change in accordance with the system's own criteria. ${ }^{65}$ In autopoietic inspired discussions, however, 'regulation' when used on its own seems to refer to the activity of controlling, governing or directing. ${ }^{66}$ Finally, biology (relevant for it forms the basis for cybernetic analyses) gives us yet another usage. 'Regulation' (which is always in this following sense always self regulation) is 'the property whereby the nature and growth of parts of an organism are interrelated so as to produce an integrated whole so an organism can adapt to shocks or its surroundings'. 67

Next we have questions of who or what is performing 'regulation', in what institutional or other form, in relation to what, and how. The categories in the table are almost indefensibly broad brush in their demarcation and identification of components, largely because what is encompassed in columns (B)-(E) is pretty much the whole of social science. Nonetheless, it is worth persevering with the mapping exercise, even if it does rather shamelessly blunder through the fundamental questions of social order and control and downplay the extent to which definitions, boundaries, interactions are open to debate, for if nothing else it indicates just how wide the preserve of 'regulation' has become, and perhaps how blundering some of us regulationists can be.

Battling on therefore, if we look at the issue of who or what is performing this activity, then we have yet another set of assumptions which are often rolled up into the definition or use of the term 'regulation'. For most, regulation is something done by government

\footnotetext{
${ }^{60}$ Oxford English Dictionary (OED).

${ }^{61}$ Selznick, P (1985) 'Focusing Organizational Research on Regulation' in Noll (ed), note 10 above, pp 363-364.

${ }^{62}$ eg Oftel, note 40 above.

${ }^{63}$ Baldwin and Cave, note 29 above, p 2.

${ }^{64}$ eg Rhodes, R (2000) 'The Governance Narrative: Key Findings and Lessons from the ESRC's

Whitehall Programme' Public Administration 78 (2): 345.

${ }^{65}$ Teubner, note 17 above, 1993, pp 20-22.

${ }^{66}$ Teubner, note 4 and 18 above.

${ }^{67}$ The New Shorter Oxford English Dictionary.
} 
actors, eg through ministries or agencies, but some have also included courts. ${ }^{68}$ For many others it is something also done by non-government actors (organisations, associations, firms, individuals, other specialist bodies, eg auditors, technical committees). For some regulation can (additionally) be performed by economic forces (principally the interactions of buyers and sellers in a market, though it can also include macro-economic factors such as inflation, foreign exchange rates, money supply etc). For yet others, 'regulation' is the action of, or outcome of, social forces, this time the usual suspects of sociology: norms, institutions, culture etc.

Finally I have included technologies, by which I mean the understanding of and ability to employ, manipulate, or alter the physical or human environment and the products of that understanding. ${ }^{69}$ Included in this broad category are both the understandings and outputs of the applied, natural and human sciences, though analyses which focused just on technologies would probably find it illuminating to separate them. Examples are the development of techniques of number theory, and so statistics ${ }^{70}$, probability theory (risk analysis), ${ }^{71}$ double entry book keeping (audit), ${ }^{72}$ tables of solar declination (navigation, hence imperial expansion and colonial control), ${ }^{73}$ engineering (steam engine, printing press, electronic engineering (hardware and software), photography (eg CCTVs), fingerprinting, understandings of the properties of the environment or biology. It also includes the design of the built environment (design and positioning of buildings - eg impact on policing). ${ }^{74}$ The role of technology in regulating is not yet part of the mainstream regulatory literature, but has been noted in diverse writings on audit, ${ }^{75}$ risk, ${ }^{76}$ the Internet, ${ }^{77}$ and on sociologies of control. ${ }^{78}$ I include it here as I think it is something that needs to be explored more systematically in the study of any regulatory system. The point is that the ability to control is hampered or facilitated by technology, that is by extent to which we do or do not have technological capacity, and by the inherent characteristics of that technology. Whether these forms of control constitute 'regulation' or whether they are simply instruments that may or may not be employed in the activity of regulation, or are an input into the overall output of interactions which constitutes regulation, is of course part of the definitional dispute.

\footnotetext{
${ }^{68}$ Collins, H (1999) Regulating Contracts, Oxford: Oxford University Press, chapter 4.

${ }^{69}$ The use of the term is thus inspired by, but not identical to, Foucault's deployment of the term. See also Rose and Miller, note 4 above; Rose, N (2000) 'Government and Control' British Journal of Criminology 40 (2): $321 \& 323$.

${ }^{70}$ Foucault, note 4 above; Rose, N (1991) 'Governing by Numbers: Figuring Out Democracy' Accounting, Organizations and Society 16 (7): 673; Latour, B (1987) Science in Action, Milton Keynes: Open University Press.

${ }^{71}$ Bernstein, P L (1996) Against the Gods: The Remarkable Story of Risk, New York: Wiley.

${ }^{72}$ Power, M (1997) The Audit Society, Oxford: Oxford University Press.

${ }^{73}$ Law, J (1986) 'On the Methods of Long-Distance Control: Vessels, Navigation and the Portuguese Route to India' in J Law (ed) Power, Action, Belief: A New Sociology of Knowledge?, London: Routledge \& Kegan Paul.

${ }^{74}$ For discussion see Garland, D (2001) The Culture of Control, Oxford: Clarendon, p 162; Shearing, C and Stenning, P (1985) 'From the Panopticon to Disneyworld: The Development of Discipline' in A Doob and E L Greenspan (eds), Perspectives in Criminal Law, Aurora: Canada Law Books.

${ }^{75}$ Power, M, note 72 above.

${ }^{76}$ Bernstein, P L note 71 above; Hacking, I (1990) The Taming of Chance, Cambridge: Cambridge University Press.

${ }^{77}$ Lessig, L (1999) Code and Other Laws of Cyberspace, New York: Basic Books.

${ }^{78}$ Law, note 73 above, Callon, M (1999) 'Domestication of the Scallops and the Fishermen of St Brieuc Bay: Some Elements of the Sociology of Translation' in J Law (ed), note 65 above; Law, J and Hassard, J (eds), Actor-Network Theory and After, Oxford: Blackwells; Rose and Miller, note 4 above, pp 183-187; Rose, note 4 above, pp 52-55.
} 
Then there is the issue of what actors, activities and/or areas of social life are being 'regulated'. As noted above, the assumption in much regulatory writing is that it is economic activity which is being subjected to regulation; the market, and actors in the market, usually firms: Ogus's definition of regulation as fundamentally 'a politicoeconomic concept'. However, as noted, regulation is for others a politico-social concept, in which governments 'regulate' non-economic areas of social life (eg dangerous dogs or paedophile registers) ${ }^{79}$ and are themselves 'regulated' by other public or private actors, ${ }^{80}$ or a social concept, in which regulation is any form of social control by actors and factors in any area of social life, broadly defined.

Finally there is the increasingly complex issue of how regulation is or can be exercised; of what instruments are 'regulatory' instruments. The 'how' of regulation, or more particularly 'how to do it better', is a burgeoning policy area and deserves separate consideration in its own right. ${ }^{81}$ For our purposes it is sufficient to note that the 'how' is obviously related to who or what it is that is seen to be doing the 'regulating'. So if it is government that is seen to be the 'regulator' then regulation is used to refer to the use of rules, legal, quasi-legal, non-legal, which may have a certain character (mandatory, facilitatory, performance, technical), which may or may not be accompanied by systematic monitoring and enforcement of sanctions for their breach. Rules and sanctions may form part of a strategy of 'command and control' regulation, of 'proceduralisation', of 'meta-regulation' or of incentive structures, tradeable permit systems, disclosure requirements, and so on. Or as the initial definitions set out above note, 'regulation' may refer to any action by government: including economic measures such as taxes, subsidies, public procurement policies, 'market based' techniques of competitive tendering for licenses, franchises or other benefits (eg extra funding for public and private bodies), or persuasive techniques such as information or education. Non-governmental actors have a similar range of instruments based on written or unwritten norms, financial measures, sanctions and suasion, excluding of course the legitimate use of force. ${ }^{82}$ Governmental and non-governmental actors may act alone or in any combination. ${ }^{83}$ If the market is seen as 'regulating' then it does so through the interactions of rational buyers and sellers. If it is the broad category of 'social forces' that is chosen as the 'regulator' then essentially the analytic tools of sociology are employed: structuring, framing, enabling, co-ordinating, ordering, etc. If it is 'technologies' then 'regulation' is through (or is the product of) the development and application of understandings of the physical and human environment - the outpourings of the applied, natural and human sciences.

Matters are further confounded by the fact that definitions vary as to whether they contain something from every column, and if not, from which columns they do take the definition. Many definitions do include something from all five columns (ie regulation = activity (A) performed by (B) taking form (C) with respect to area (D) using mechanism (E)). For example, one very common definition of regulation, particularly in

\footnotetext{
${ }^{79}$ Hood, C, Rothstein H and Baldwin, R (2000) The Government of Risk, Oxford: Oxford University Press.

${ }^{80}$ Hood et al, note 42 above; Braithwaite and Drahos, note 25 above.

${ }^{81}$ See eg Baldwin \& Cave, note 29 above, Hood et al, note 42 above, Gunningham and Grabovsky, note 42 above to name but a few.

${ }^{82}$ See eg Daintith, T (1988) Law as an Instrument of Economic Policy, Berlin: de Guynter, pp 25-47.

${ }^{83}$ See eg Gunningham and Grabovsky, note 42 above.
} 
the US, takes this composite form: regulation is defined as the activity of (A) controlling (B) by government (C) through a separate agency (D) with respect to business (E) using rules. ${ }^{84}$ Other definitions are more parsimonious. For example, some would argue that 'regulation' is one of the definitions in (A), eg a process of controlling or directing, via one particular instrument in (D), ie rules, but would not see anything in columns (B), (C), or (D) as definitionally relevant. Definitions also vary as to the rows they incorporate. For some only governments regulate. For others, regulation is an intentional activity, so only actors regulate - technologies, 'social forces' do not. They may be tools that those regulating might use, or indeed be constrained by, but of their own volition, as it were, economic forces, social forces or technologies do not 'regulate', they affect the activity of regulating or the outcome of the interactions that constitute regulation. Some specifically exclude anything that affects non-economic life, as noted above.

It might be asked, does this definitional free-for-all matter? Isn't preoccupation with definitions very 'modern' - in the sense of not post-modern and so hopelessly old fashioned? Moreover, is it not better to have a broad definitional scope than a narrow one? After all, it was the very narrow definition of 'regulation' employed particularly by US writers that led to the incredibly irritating and futile 'regulation', 'de-regulation' 're-regulation' debate of the 1980s. ${ }^{85}$ But whilst narrowness can stultify thought, breadth can bring incoherence. It has been said that concepts are more important for what they do than for what they mean. ${ }^{86}$ They provide a cognitive frame, an institutionalised set of meanings that channels thought and action in particular directions. ${ }^{87}$ Their value lies in the way they are able to provide a purchase for critical thought upon contemporary problems. ${ }^{88}$ I would agree. But what cognitive frame is set up, what purchase for critical thought provided, and on what problem, by the invocation of the concept 'regulation'?

\section{Conceptualising 'regulation'}

It could be argued that given the conceptual confusion and general baggage that accompanies the term 'regulation' we should not bother to pursue the analysis further. We should just switch to using a different term: 'governance', for example, or 'control'. But that is a very unsatisfactory response, because it simply shifts the debate to the level of contesting labels. What is important is understanding the concepts to which those labels might refer. Moreover, given that any of the likely candidates (eg 'governance' or 'control') are themselves given a wide range of meanings in different socio-linguistic communities (or perhaps, like regulation, no meaning at all), simply choosing another label does not solve the problem, for it remains to be explained what, if any, concept lies underneath that label in any one of those communities. What is important is not what we call the activity or phenomenon that is the subject matter of inquiry or analysis, but what it is. What label we attach to it is if secondary importance, significant only if the label attached by one community affects the ability of that concept to be readily

\footnotetext{
${ }^{84}$ See eg Noll, R 'Government Regulatory Behaviour: A Multidisciplinary Survey and Synthesis' in R Noll (ed), note 10 above, p 3.

${ }^{85}$ For a review see Majone (ed), note 58 above.

${ }^{86}$ Rose, note 4 above, p 9.

${ }^{87}$ Connolly, W (1983) The Terms of Political Discourse, $2^{\text {nd }}$ ed, Oxford: Robertson, $p 1$.

${ }^{88}$ Rose, note 4 above, p 9.
} 
recognisable, or acceptable, by another (because the label has a quite different meaning, or carries particular normative overtones, in that socio-linguistic community).

It should be clear from the discussion above that if we want to try to understand how particular forms of control are exercised throughout contemporary society and how patterns of ordering are structured and facilitated, and if we want to highlight aspects of those activities which we think are in some sense important or significant, we will need an understanding of 'regulation' (or whatever label we choose to adopt) which does not see it as a uniquely state activity. If 'regulation' remains a concept tied inherently to the state, then in trying to analyse it we will find contemporary forms of rule hard to understand, if indeed we recognise them at all. We have to ask the question: what understanding do we need if we are to take seriously the decentring analysis of the nature of state-society and intra-society relations, and if we are to develop a conceptualisation of 'regulation' (or its competitor labels) that is compatible with that analysis?

To start answering that question, we can embark on an admittedly semantic game of definition building. Let me make it clear: it is not sought to impose on the broad field of inquiry that goes under the heading 'regulation' a particular definition that all will adopt, though one is suggested. Nor, it is suggested, will we learn much about what 'regulation' is as a social practice through this semantic exercise. Rather, the aim is to provoke an analytical debate about what social activity or phenomenon those who purport to analyse regulation, and to prescribe 'better' forms of regulation, are talking about. We can begin by asking how we should define 'regulation', in functional terms, in essential terms or in conventionalist terms. ${ }^{89}$ A functional definition is based on the function that 'regulation' performs in society (in the Durkheimian sense of how it contributes to the survival of society as a whole): 'regulation does...'. An essentialist definition identifies central facets of the phenomenon and says that when they are present, then the phenomenon may be termed 'regulation': 'regulation is...'. A conventionalist definition looks to the way that the term is used in practice, and where the community being considered identifies something as 'regulation', that is the definition ascribed: 'regulation is used to mean...'.

One of the most common definitions of regulation is functional: controlling economic activity, or even more narrowly, particular forms of economic activity (public utilities). But here we run into the problem of under-inclusiveness: there may be other mechanisms performing closely related functions in non-economic areas and by nonstate actors which seem indistinguishable from those to which we are applying the term 'regulation'. Indeed the central point of the decentring analysis is just that: that 'regulation' is not just the function of control as performed by the state, but is the function of social control performed by others as well, and the object of that control in many regulatory writings is not confined to economic life. Alternatively, the function that 'regulation' performs could be broadly cast as that of social control. This runs into the danger of being so broad that it contributes nothing. Cybernetic-based approaches, associated most strongly in the regulation literature with Hood, are useful in providing some specification as to what 'social control' entails. ${ }^{90}$ In that analysis, 'control' is

\footnotetext{
${ }^{89}$ For a discussion of the question 'what is law' in these terms see Tamanaha, B (1997) Realistic SocioLegal Theory: Pragmatism and A Social Theory of Law, Oxford: Clarendon pp 89-128.

${ }^{90}$ Hood, C (1986) Administrative Analysis, Brighton: Wheatsheaf; Hood, Rothstein and Baldwin, note 79 above, pp 23-24.
} 
means the ability to keep the state of a system within some preferred subset of all possible states. ${ }^{91}$ Any system of control in art or nature has to have the capacity to perform three functions: standard setting, information gathering and behaviour modification. In the absence of any one of these, there is not 'control' in a cybernetic sense. Transposing this analysis to regulation proceeds thus: regulation is a system of control, and thus regulation entails the capacity for performing those three functions. This definition has an intuitive appeal: most would associate regulation with the presence of standard setting, monitoring and enforcement components. However, the definition covers all systems of social control: social norms or culture are potentially as 'regulatory' as legal rules. There is no distinction, for example, between systems of control that involve a role for human design or intentionality, and those which do not. It further runs into the problem of any functional definition: it assumes a level of effectiveness which may in practice be absent. The identification of something as 'regulation' becomes not an analytical exercise but an empirical one as it is dependent on empirical assessment as to its effectiveness before it can be said to satisfy the definition.

Functional definitions overlap with (or are a form of) essentialist definitions. An essentialist approach asserts that 'regulation is...'. It identifies elements that have an analytical relationship to the concept, here regulation, in an attempt to specify an invariant set of necessary and sufficient conditions for the application of the term 'regulation' without which it is logically inconsistent to assert that it is properly applied. It further distinguishes these analytic conditions from those conditions that are simply open to empirical investigation (synthetic). ${ }^{92}$ An essentialist definition could be, for example, that regulation is a form of institutionalised norm enforcement (as in some definitions of law), perhaps additionally that it is performed by the state over economic life through non-judicial institutions. A different definition would include institutionalised norm enforcement to be the analytical core, but see the question of whether regulation is performed by actors other than the state, or whether it is performed with respect to economic activity alone, to be questions which are open to empirical verification.

We could ask is the application of the analytic - synthetic dichotomy misplaced? Is regulation instead a 'cluster concept'? That is, to adopt Connolly, a concept which, first, is comprised of a broad range of ingredients, any large set of which grouped together in a particular act or practice is capable of characterising the phenomenon as 'regulation', but any one of which might be missing in a particular instance where people would otherwise agree that 'regulation' properly applies, ${ }^{93}$ and secondly, those ingredients themselves make reference to new concepts which are themselves complex, and to which, to make the concept of 'regulation' intelligible, we must display its connections. $^{94}$ So, for example, is it the case that if three or four of the following are present, then what we are observing is 'regulation': deliberate attempts to influence behaviour; an emerging pattern of interactions; legally enforceable rules; standard setting; information gathering; enforcement; cultural restraints upon behaviour; government intervention; interventions in the market? The broad range of uses given to the term 'regulation' suggests that of the forms of definitions it would be easiest to gain

\footnotetext{
${ }^{91}$ Hood, ibid., p 112.

${ }^{92}$ Connolly, note 87 above, pp 14-20.

93 Ibid.

${ }^{94}$ Ibid, 14, pp 17-20.
} 
support for 'regulation' as a cluster concept, though given that anything in the table is a potential ingredient, it would be an extremely cluttered one.

Both functional and essentialist definitions are de-contextualised, generalised abstractions. They seek to identify central elements of the phenomenon in issue, here 'regulation', and abstract from them build up the definition. In contrast, a conventionalist definition is one which is embedded in current practices, rather than abstracted from them. It asks 'what is regulation used to mean' in a particular community. ${ }^{95}$ The table set out above of the different uses of 'regulation' adopts such a conventionalist approach. Taking the English-speaking academic and policy community as its base, it asks how is the term 'regulation' used by that community. Such an approach avoids the problems of over- and under-inclusiveness which arise from generalised abstractions, but as the table indicates, it raises other difficulties. Not least it may result in a definition which is unwieldy for analytical purposes, as not all in a particular interpretive community are likely to agree on the meaning. It also produces only a contextual definition, making comparisons across interpretive communities difficult other than at the level of comparing definitions - a piece of self analysis which may be diverting for academics but does not really get us very far in understanding a social phenomenon.

Do we want any more analytical rigour, and if so why? The answer lies in what it is we want the concept to do, or rather what we want to do with it, rather than what the concept 'means' in some fundamental sense. The argument here is that we need a conceptualisation of regulation (or, to reiterate, a competitor label) that provides us with a tool of inquiry into a particular social phenomenon, delimiting, and constructing, the area and scope of that inquiry, both to facilitate analysis, and to facilitate practical discussions of how regulation might be improved in some way.

\section{Developing a decentred definition of regulation}

What are those who study and practice regulation concerned with, and why are many so concerned to characterise what they see as 'regulation'? Those who study regulation are concerned with description, critique, and often prescription, as with any academic inquiry. But description and critique of what? Of any 'thing' that structures or constrains the behaviour of individuals, organisations, or systems? If so, then clearly a wide ranging conception of regulation is needed, and of course once provided is selfvalidating for it then itself necessitates and justifies such a broad inquiry. Such a conception would embrace everything on the table. But, as noted above, that simply relabels almost all questions of social and political science questions of regulation. Academic colonisation by re-branding.

Or are we, and should we be, concerned with intentional attempts to control or order people or states of affairs (albeit mindful of the unintended consequences of those intentions)? I would argue we should be so concerned: 'regulation' is otherwise indistinguishable from all other questions of social control and ordering. To reflect this, regulation could be defined as 'the intentional activity of attempting to control, order or influence the behaviour of others'. Such a definition uncouples the activity of intentionally attempting to control etc from the actor of government, so enabling a

\footnotetext{
${ }^{95}$ For the adoption of such an approach to defining law see Tamanaha, B (2000) 'A Non-Essentialist Version of Legal Pluralism' Journal of Law \& Society 27 (2): 296.
} 
decentred understanding of regulation. However, by retaining an element of intentionality it excludes the categories of market forces, social forces and technologies.

It is still broad, however. A stronger purposive dimension would combine an intentional dimension with a problem-solving or goal-attaining orientation, and a temporal dimension would indicate extension of the activity in time. A definition would be thus: 'regulation is a process involving the sustained and focused attempt to alter the behaviour of others with the intention of producing a broadly identified outcome or outcomes'. Such a definition is less specific than the cybernetic definition, in that it does not require that certain control elements be present (standard-setting, information-gathering and behaviour-modification) for 'regulation' to be said to exist, if only in unsophisticated form, and leaves for empirical investigation whether in order to achieve that goal of modifying behaviour (or in cybernetic terms, keeping a system in one of a range of its possible states) what is required is the effective capacity for each of those tasks.

But in identifying those tasks, the cybernetic definition does provide a valuable degree of specificity. Without that, there is at the least a danger that regulationists will interpret 'regulation' too narrowly in identifying and analysing it, focusing for example only on the standard setting component and omitting other aspects: the criticism levied by implementation analysis against the traditional approach in public administration. ${ }^{96}$ Taking this point on board, we could instead combine the task aspects of the cybernetic definition of regulation with the temporal, intentional and problem-solving aspects suggested above, (so excluding the operation of market forces or social norms or cultural worldviews from the definition), but without assuming that there is in fact the effective capacity to achieve the tasks identified. The definition, an essentialist one, would thus be: 'regulation is the sustained and focused attempt to alter the behaviour of others according to defined standards or purposes with the intention of producing a broadly identified outcome or outcomes, which may involve mechanisms of standard-setting, information-gathering and behaviourmodification.'

In terms of delineating both an academic task and an area of social and political activity, my inclination is that this definition has much to commend it. What label is attached to it is, as I have emphasised, of secondary importance. It does not assume that there has to be a capacity for mechanisms of standard-setting etc that is effective for the phenomenon to be 'regulation'; if they are not effective then what that phenomenon will be is simply ineffective regulation. It treads a path between overand under-inclusiveness, distinguishing regulation from any system of social control on the one hand, and extending it beyond state activity, particular institutional arrangements or intervention in a particular area of life on the other. It thus delimits 'regulation' as an intentional, systematic attempt at problem-solving, so marking it out as a specific site of social activity and thus of investigation. Whilst the patterns of interaction of rational actors, or social norms or cultural world views, or technologies might be influential in how regulatory systems operate, and whilst regulatory systems might seek to harness these or to alter them, they are not in themselves regulation. The definition does not however see that activity as necessarily confined to the state.

\footnotetext{
${ }^{96}$ See Hood, Rothstein and Baldwin, note 79 above, $\mathrm{p} 15$.
} 
Regulation is an activity that extends beyond the state, thus regulation may on the basis of such a conceptualisation embrace a variety of forms of relationship between state, law and society. It thus enables the identification, creation and analysis of regulatory arrangements that involve complex interactions between state and nonstate actors, and enables each to be identified as both regulators and regulatees. It thus enables a coherent analysis of 'decentred' regulation to be developed, along with prescriptions as to how it is or might be effected. Finally, it does not presume that there is a particular problem that 'regulation' is being used to address: 'regulation' is not the project of, for example, welfare economics, or addressing the concerns of the risk society.

That said, definitions are not neutral; they come with their own assumptions, theoretical and/or empirical, and their own conceptual baggage. This is so whichever label and whichever substantive conceptualisation is adopted. Those assumptions deserve at the least to be recognised, for they will have a bearing on whether the theoretical paradigms that might be used to explore the social activity are in fact consistent with the way that activity has been identified and indeed constructed in the definition. The definition of regulation given above sees regulation as a form of intentional, problem-solving activity, distinguished from other problem-solving activities (like maths) in that it attempts to alter the behaviour of others using a range of mechanisms. It attempts, however, not to foreclose which theoretical paradigms might be used to analyse the activity which it defines. It has a role for intentionality, but it does not necessarily require critical self-reflection, however. It thus seeks to leave room for theories which deny any significant role for agency in social action and interaction (eg cultural theory, systems theory, and some strands of discourse analysis and institutionalism). However, the definition is also compatible with rationalistic accounts of social action: that regulation is the result of the interactions of rational actors in the political and bureaucratic marketplace. It does not however require such accounts. The definition does not assume that problems are correctly identified, that decisions are rationally reached, or indeed that attempts are successful. Nor does it assume that social structures will not play a role in forming interests or setting boundaries of appropriateness. Finally, the definition is consistent with a theory of structuration or similar, ie of a relationship between structure and agency in which each influences and is influenced by the other. It is thus compatible with those strands of institutionalism, for example, or of discourse analysis which adopt such a perspective.

\section{Critiquing decentred regulation}

Definitions, it was suggested above, are useful for they assist in the tasks of inquiry, critique and prescription. Inquiry we have just been discussing; what of critique and prescription? Critiques of regulation take two principal forms: that of effectiveness and that of values. Of these, it is effectiveness that dominates much of the regulation literature in policy and academic circles. The effectiveness critique is that regulation is or is not 'working' either at all or as well as it might: it is not achieving what it set out to achieve. Critique is usually accompanied by prescription as to what techniques should be used instead, with greatest attention given in most recent literature to the 'decentred' techniques noted above. The values-based critique is that regulation is not directed at the appropriate goals, and/or that it is not being pursued in accordance with, or made subject to, certain values. The former tends to be a critique of the 
positioning of welfare economics as an exclusive set of prescriptive goals for regulation, and the need to temper the pursuit of such economic goals with the pursuit of other social values, for example universal service in utilities, or 'public service' in broadcasting, ${ }^{97}$ or more broadly the access to 'justice' in some form. ${ }^{98}$ The latter is that in its operation regulation should recognise and incorporate certain values and in so doing will become legitimate.

There is a clear interrelationship between what one identifies as the social activity being critiqued and the form of critique one wants to make; each will shape the other. In particular, it is suggested that both the effectiveness and the values-based critique are important forces behind the expansive, decentred understanding of regulation, and indeed of governance. Above it was suggested that decentred understandings were driven by a conceptual reorientation of the role of the state and of the nature of interactions in society. It is further suggested that they are also driven by the search for more effective forms of regulation, and, crucially, by the recognition that there is a particular form of social activity occurring which should be subjected to certain values. In other words, a social phenomenon or activity is sometimes characterised as 'regulation' because the characteriser wishes to impose certain values on it. However, labels are often relied upon to make the argument. Thus designating something as 'regulation' can be implicitly meant to analogise 'regulators' with 'governments'; demands that regulation be subjected to the same norms as government action then inexorably flow. The need for accountability, for example, becomes self-validating just by our identification of a practice as 'regulation'. To the extent that this occurs it is regrettable: if we want to invoke a values-based critique we should do so specifically and justify that critique separately; we should not seek to piggyback on the value claims that might be invoked by the analogy, and simply hope that the analogy will be made. Indeed, which values it is appropriate to apply to the practices of decentred regulation and just how these should be attained are the most troubling, and the least worked through, questions relating to the decentring analysis.

\section{Law and regulation}

Regulation exists within a web of concepts, and as post-structuralists have long been telling us, terms gain their meaning from their difference from other terms. Whether or how 'regulation' differs or should differ from governance or management is an issue that lies for another time. The relationship that is focused on here is that of regulation and law. What does this discussion of regulation, and the adoption of the decentred conceptualisation set out above, mean for an understanding of the relationship between law and regulation? Only a brief consideration can be given here. The exact nature of the relationship, to state the obvious, depends on the conceptualisation of both that is adopted. There is as little and as much agreement as to what 'law' is as there is as to what 'regulation' is. That said, centred analyses of regulation and centred analyses of law are likely to differ less, or at least in a different way, with each other than they will with decentred analyses of either. Similarly, decentred analyses of regulation will have clear similarities with decentred or pluralistic conceptions of law than they will with centred conceptions, in that the former both detach the activity of the state from the definition of their central concept.

\footnotetext{
${ }^{97}$ On the latter see Born, G and Prosser, T (2001) 'Culture and Consumerism: Citizenship, Public Service Broadcasting and the BBC's Fair Trading Obligations’ Modern Law Review 64 (5): 657. 98 eg Parker, C (1999) Just Lawyers, Oxford: Oxford University Press.
} 
But there is no settled definition of 'law' within legal pluralism, just as there is none of regulation. Legal pluralists are agreed that 'law' does not solely emanate from the state; just what it is and how it is distinguished from other forms of norm-based social ordering is still contested. ${ }^{99}$

At their most broad, definitions of law and regulation could simply be redescriptions of one another. The definitions of law adopted by many legal pluralists are that law is concrete patterns of social ordering, ${ }^{100}$ the spontaneous rule-bound order of the "semiautonomous social field' ${ }^{101}$ or the set of norms which actors abstract from practice and invest with binding authority. ${ }^{102}$ These coincide with a definition of regulation as 'forms of social control available to harness a wide range of actors in addressing a particular problem or set of problems as patterns of social ordering, ${ }^{103}$ How to distinguish between types of patterns of ordering or forms of control, and once distinguished how to conceptualise the relationships between them, are then questions with which both legal pluralism and decentred regulation have to grapple.

Nonetheless, regulation is often distinguished from law, albeit implicitly. For many lawyers, particularly those still in the grip of what Twining has described as the 'monist..., statist... and positivist' tradition of law, ${ }^{104}$ 'regulation' is 'less than law' in that it is a simply a species of the genus 'law'. It is that part of law that is instrumentalist in orientation, and contained in the mass of technical statutes, statutory instruments and other secondary and tertiary rules that set out, often in intimidating detail, standards of conduct to be followed.

Some regulationists might contend that regulation is not 'less than' law at all, rather the relationship is reversed: law is simply a technique or instrument that may or may not be involved in the practice of regulation. That contention is discussed below. But even if we accept that regulation is no more than legal rules, are regulatory legal rules distinguishable from other legal rules, such that the former may be said to be simply a sub-set of the whole? There may be some intuitive appeal in the distinction: surely doctrines of consideration in contract law are far removed from the strictures of health and safety legislation, for example. But once we start to probe, the distinction between regulatory and non-regulatory law might be hard to pin down. Clearly it is not sufficient to distinguish between statute and common law, identifying the former as regulatory and the latter as not, not least because common law has itself embraced and developed around principles introduced by statutes. Basing the distinction on whether

\footnotetext{
${ }^{99}$ The literature is extensive: central texts include Moore, S F (1978) Law as Process: An Anthropological Approach; Galanter, M (1981) 'Justice in Many Rooms: Courts, Private Ordering, and Indigenous Law' Journal of Legal Pluralism 19: 1; Griffiths, J (1986) 'What is Legal Pluralism?' Journal of Legal Pluralism 24: 1; Merry, S E (1988) 'Legal Pluralism' Law and Society Review $22 \mathrm{p}$ 869; de Sousa Santos, B (1995) Towards a New Common Sense, London: Routledge; Teubner, G (1992) 'The Two Faces of Janus: Rethinking Legal Pluralism' Cardozo Law Review 13: 1443; Teubner, G (1997) “Global Bukowina': Legal Pluralism in the World Society' in G Teubner, (ed) Global Law without a State, Aldershot: Dartmouth.

A recent survey and comment is provided by Tamanaha, B (2000) 'A Non-Essentialist Version of Legal Pluralism' Journal of Law \& Society 27 (2): 296.

100 Galanter, ibid.

${ }^{101}$ Moore, above note 99.

${ }^{102}$ Ehrlich, E (1922) 'The Sociology of Law’ Harvard Law Review 36: 130; Malinowski, B (1926) Crime and Custom in Savage Society, London: Routledge \& Kegan Paul; Griffiths, above note 101 ${ }^{103}$ Gunningham and Grabovsky, above note 42.

104 Twining, W (2000) Globalisation and Legal Theory, London: Butterworths, p 232.
} 
or not the statute is 'old' and thus has had time to be included in the 'sedimentation' of the common law ${ }^{105}$ simply brings the distinction down to the contingency of time; where then is the cut off point between law and regulation: 1860, 1980?

Is the distinction that different parts of law have a different orientation? It is common to distinguish between private, formal law, and 'public', regulatory law. ${ }^{106}$ Traditional private, formal, law, encodes basic rights and obligations that facilitate social interactions but do not direct them. 'Public', regulatory, or material law is law that encodes the principles, and instrumentality, of the welfare state. ${ }^{107}$ The argument that regulation is 'less than' law assumes that the two forms of law coexist, but are distinct. But as Collins's recent work on contract law illustrates, the different forms are indistinct both conceptually and empirically. ${ }^{108} \mathrm{He}$ contends that private law could never be non-instrumentalist or 'value-neutral', but notwithstanding that, that private law has increasingly been affected by shift to instrumentalism consequent on the expansion of public regulation. In this shift, formal, private law is subjected to a process of productive disintegration in which new capacities and evolutionary trajectories for public regulation are produced, and the collision between formal and material law, or private law and public regulation, results in a new style of legal discourse. $^{109}$ So maintaining a distinction between law and regulation on the basis that different 'types' of law have different orientations involves the assumption that 'formal law' exists unadulterated by instrumentalist concerns, and a categorisation of law that portrays a relationship which is closed and static, omitting the nature and consequences of their interaction on each other.

Regulation may be argued to be 'less than law' in functional terms. On most conceptualisations of regulation, 'regulation' does not, or at least not primarily, perform the functions of dispute resolution, stabilising and adapting expectations, allocating authority and the "juristic method"110 (although it may involve those in its operation or they might be its incidental effects). As such, regulation performs only one of Karl Llewellyn's law jobs, being closest to that of 'net positive drive': the organisation and harmonisation of activity within a group so as to provide direction and incentives to its members. ${ }^{111}$ Regulation, on this definition of both law and regulation, is thus 'less than' law in that the function that it primarily performs is only one of the functions of law. On other understanding the functions of law and regulation are quite distinct (though each performs the general function of facilitating system integration). Luhmann, for example, defines law in functional terms as stabilising expectations; ${ }^{12}$ regulation in contrast is implicitly seen not a separate

\footnotetext{
${ }^{105}$ The phrase is Murphy's: Murphy, WT (1997) The Oldest Social Science? Configurations of Law and Modernity, Oxford: Clarendon.

${ }^{106}$ Teubner, note 33 above.

${ }^{107}$ The proposal for reflexive law was that law had to move to the forms of indirect technique outlined above

${ }^{108}$ Collins, note 68 above. See also Teubner, G (1998) 'The Many Autonomies of Private Law' Current Legal Problems 49 p 393.

109 ibid.

${ }^{110}$ Llewellyn, K (1940) 'The Normative, the Legal and the Law Jobs: The Problem of Juristic Method' Yale Law Journal 49 p 1355.

${ }^{111}$ Ibid.

${ }^{112}$ Luhmann, N (1985) A Sociological Theory of Law, London: Routledge \& Kegan Paul; id., Social Systems (1996) (translation), Cambridge.
} 
system but simply an example of the attempt by the political system to influence the operation of other systems using the medium of law.

A further, and perhaps stronger, sense in which 'regulation' is for some lawyers seen as 'less than law' is that regulation, however it is defined, has no claim to be unified, or coherent, or marked with its own style of reason or argument, or based on consistent values or principles. Nor does it invoke or lay claim to any mystique or even legitimacy. There is no theory of the 'rule of regulation' as there is of the 'rule of law', and there is no regulatory equivalent to Hercules. ${ }^{113}$ Regulationists, and others, do not expect regulation to be internally rational or consistent; it might be, more likely it will not. But no significance attaches to either conclusion (though regulationists might worry about the impact of such inconsistencies on regulation's effectiveness). In contrast, such internal unity and consistency it is central to many understandings of law. Equating law with regulation, or at the very least arguing that a significant component of the genus law is the species regulation, challenges the idea of a specifically legal form of argument, of reason, and of interpretation. After all, it is in the spirit of debunking that Goodrich argues that law is merely regulation, that it reflects nothing grander than its own rhetoric, and is simply a mass of technical rules with no central coherence, no grounding in principle, and no overarching systems of reason. ${ }^{114}$ This is not at all troubling for regulationists or for conceptualisations of regulation. It is deeply troubling for many conceptualisations of law. As Cotterrell argues, the significance of regulation for legal theory is that it is both the cause and the manifestation of the internal fragmentation of law. ${ }^{115}$ Further, even identifying some part of law to be regulation promotes an instrumentalist view of law, which in turn demands a different task for law and legal theory, a point also made by Collins. ${ }^{116}$ To quote Cotterrell, '[1]aw's formal rationality, its consistency as a unified body of doctrine and its coherence as a principled structure of ideas seem less vital than they once did. The main value of a particular legal precept is in its usefulness for the specific goal or goals it is thought to serve., ${ }^{117}$

So even if regulation is seen as 'less than law', that relationship may be a troubling one for law; that problematic is only enhanced if law is seen to be simply equivalent to, or part of regulation. For regulation may also be seen as 'more than law'. The notion that regulation is 'more than law' is strongest if a decentred conception of regulation is invoked and set in relation to a centred conception of law: regulation is then clearly 'more than' law. But even conceptualisations of regulation that are statecentred see regulation as extending well beyond legal rules and precepts, courts, legislatures and the legal profession. However, the differences narrow again if a decentred conception of regulation is set in relation to a pluralist conception of law, as noted above.

It could be countered that whilst regulation may be 'more than law' in that law is only one of the techniques that may or may not be involved in regulation, in academic terms when regulationists look at legally based regulation they are in fact engaged in

\footnotetext{
${ }^{113}$ Dworkin, R (1986) Law’s Empire, London: Fontana.

${ }^{114}$ Goodrich, P (1990) Languages of Law, London: Weidenfeld.

${ }^{115}$ Cotterrell, R (1995) Law's Community, Oxford: Clarendon.

${ }^{116}$ Collins, above note 68 .

${ }^{117}$ Ibid., 282; see also Daintith, T (1988) 'Law as a Policy Instrument: A Comparative Perspective' in T Daintith (ed), Law as an Instrument of Economic Policy, Berlin: De Gruyter.
} 
the same practice as socio-legal scholars: both are concerned with 'law in action' rather than 'law in the books'. There is clearly an overlap between the two projects, not least because the two might be looking at the same set of social activities, though how they define their object of investigation may differ. However, there is likely still to be a critical difference between socio-legalists and regulationists, or at least those at the theoretical end of inquiry, linked to the argument above. For even where each asks the same questions, they do so for different reasons. Regulationists are not (and by implication socio-legalists are) concerned with how law sees itself, or explains itself to itself, or should do either of those things. So not only is regulation not just law in that it extends well beyond courts and legal instruments, regulationists are just not concerned with law in that they are not concerned with whether or not law is correct in seeing itself as characterised by unity, coherence or particular modes of reasoning, or explaining itself in these or any other terms.

The relationship between law and regulation is in short as shifting and complex as the conceptualisations ascribed to each. Most conceptualisations of regulation, however, even those that see regulation as simply legal rules, are challenging for unitary conceptions of law, and indeed for law's understanding of itself. This is so even on the narrowest conception of regulation (as a form of legal rule) because the prevalence of regulatory law requires the acceptance by legal theory of an instrumentalist view of law, which in turn poses a different set of questions about the legal system (those of effectiveness rather than coherency), ${ }^{118}$ and because of the disintegrating, yet productive, effect that regulatory law has on formal, private law. ${ }^{119}$ The implications for legal theory are for some form of pluralist understanding, ${ }^{120}$ but whether that is Teubner's poly-contextuality, ${ }^{121}$ or Cotterrell's version of legal pluralism, ${ }^{122}$ or some other form, is a matter of current debate. What should be clear is that adopting a pluralistic approach to both law and regulation challenges both to answer how, once they have become analytically detached from the state, they are distinguishable from any other form of social control, as well as each other. As Murphy has expressed it with regards to law, 'the question is not whether law can survive without hierarchy but rather how law can learn to understand itself in a world of horizontally rather than hierarchically configured relations'. ${ }^{123}$ As should be clear, the same might be said for regulation.

\footnotetext{
118 Ibid.

${ }^{119}$ Collins, note 68 above.

${ }^{120}$ eg Cotterrell, note above, p 280, 310-311.

121 Teubner, op. cit. note 108 .

${ }^{122}$ His theory of legal pluralism proceeds by analogy. The concept of law that he argues is most useful for dealing with the problems posed by the theory and empirical studies in the sociology of law is 'one which treats state law as central to the concept of law in modern industrialised societies but treats other normative systems as directly comparable and closely related theoretically in a kind of regulatory continuum': ibid, p 36.

${ }^{123}$ Murphy, note 107 above, p 184.
} 


\section{Conclusion}

A decentred understanding of regulation is thus both stimulating and perplexing. It has significant implications for our understanding of regulation, requiring us to face squarely the issue of what it is that we are looking at, and looking for, when we seek to analyse 'regulation'. Analyses of the patterns of ordering and control in contemporary society mean that state-centred conceptions of regulation will not suffice, and those that simply have an 'add-on' to allow for self-regulation are too limited, not least because there is no commonly accepted usage of 'self-regulation'. ${ }^{124}$ In contrast, those that equate regulation with any form of social ordering embrace too much, and so contribute too little. Simply abandoning 'regulation' and adopting a different label will not help, for it still leaves us grasping for a way of understanding particular forms of control and ordering in the framework of a decentred understanding of state-society and intrasociety relations.

Developing a clear, decentred conceptualisation of regulation on the lines suggested above may thus assist us in better understanding contemporary socio-political relations. It will at least help academics and policy makers to talk amongst themselves even in situations where the term 'regulation' has itself no resonance, and to envisage a wider range of policy potentials which do not rely on a role for the state. It also, however, unsettles our understandings of where the forces of legitimacy, authority, or power are located in society. Whilst 'regulation' can resonate with Weberian overtones of technicality, managerialism, means and ends, it also resonates with a sense of material power and effect. Decentred understandings of regulation thus require us to find answers to what values regulation should be made subject to, and how, if those issues of power, authority and legitimacy are to be addressed.

\footnotetext{
${ }^{124}$ For discussion see Black, J (forthcoming) 'Decentring Regulation: The Role of Regulation and Self Regulation in a "Post-Regulatory" World' in Current Legal Problems, Oxford: Oxford University Press.
} 